\title{
Endovascular repair combined with staged drainage for the treatment of infectious aortic aneurysm: a case report
}

\author{
Zhaoxiang Zeng ${ }^{1 \dagger}$, Zhenjiang $\mathrm{Li}^{1,2 \dagger}$, Yuxi Zhao ${ }^{1 \dagger}$, Junjun $\mathrm{Liu}^{1,3}$, Jiaxuan Feng ${ }^{1}$, Zaiping Jing $^{1}$ and Rui Feng ${ }^{1 *}$ (D)
}

\begin{abstract}
Background: Infectious aortic aneurysm, defined as a focal dilation of an infectious arterial wall, is an uncommon life-threatening disease. Compared with open surgery, endovascular repair yields acceptable clinical outcomes. However, residual tissue infection may increase the risk of secondary intervention. Here, we present a successful case of endovascular repair combined with staged drainage for the treatment of infectious aortic aneurysm.

Case presentation: A 58-year-old man presented to hospital with a 3-day history of lower back pain radiating to the back associated with fever. The dynamic imaging characteristics revealed rapid progress of infectious abdominal aortic aneurysm with negative blood culture. The patient underwent endovascular repair and salmonella enteritidis was identified through drain culture.
\end{abstract}

Conclusions: Endovascular procedure and staged drainage can be feasible and effective option in selected cases.

Keywords: Infectious abdominal aortic aneurysm, Aortitis, Pseudoaneurysm, EAVR, Case report

\section{Background}

Infectious aortic aneurysm (or mycotic aortic aneurysm) is defined as a focal dilation of an infectious arterial wall. It is an uncommon life-threatening disease [1]. It is essential to establish an early diagnosis of infectious aneurysms for timely treatment to improve survival and long-term prognosis. Radiological imaging is critical for detecting initial aortic infection. However, the changes in early images may be minimal, making them easy to be neglected or mixed up [2]. We reported a case with complete sequential typical images of infectious abdominal aortic aneurysm in different stages recorded by series computed tomography (CT) scans, and the patient

\footnotetext{
* Correspondence: 320165900@qq.com

'Zhaoxiang Zeng, Zhenjiang Li and Yuxi Zhao contributed equally to this work.

'Department of Vascular Surgery, Changhai Hospital, Navy Medical University, Changhai Road 168\#, Yangpu District, Shanghai, China

Full list of author information is available at the end of the article
}

was successfully treated by endovascular procedure and staged drainage.

\section{Case presentation}

A 58-year-old man presented to the emergency department with a 3-day history of lower back pain radiating to the back associated with fever $\left(39.7^{\circ} \mathrm{C}\right)$. The physical examination was unremarkable. He has a medical history of diabetes and current cigarette smoking. On admission, enhanced computed tomography angiography (CTA) revealed a moderate atherosclerotic infrarenal abdominal aorta with thickened aortic wall and periaortic fat stranding (Fig. 1a, 2a). A laboratory investigation showed that leukocyte count was normal, while the ration of lymphocytes decreased to $18.2 \%$ and eosinophil count was 0 . The erythrocyte sedimentation rateand $\mathrm{C}$-reactive peptide were elevated $(34 \mathrm{~mm} / \mathrm{h}$ and $138 \mathrm{mg} / \mathrm{L})$. The serum IgG4 level was within the normal range. The standard bacterial and mycobacterial blood cultures were negative. Nevertheless, infectious abdominal aortic disease was

(C) The Author(s). 2020 Open Access This article is licensed under a Creative Commons Attribution 4.0 International License, which permits use, sharing, adaptation, distribution and reproduction in any medium or format, as long as you give appropriate credit to the original author(s) and the source, provide a link to the Creative Commons licence, and indicate if changes were made. The images or other third party material in this article are included in the article's Creative Commons licence, unless indicated otherwise in a credit line to the material. If material is not included in the article's Creative Commons licence and your intended use is not permitted by statutory regulation or exceeds the permitted use, you will need to obtain permission directly from the copyright holder. To view a copy of this licence, visit http://creativecommons.org/licenses/by/4.0/. The Creative Commons Public Domain Dedication waiver (http://creativecommons.org/publicdomain/zero/1.0/) applies to the data made available in this article, unless otherwise stated in a credit line to the data. 

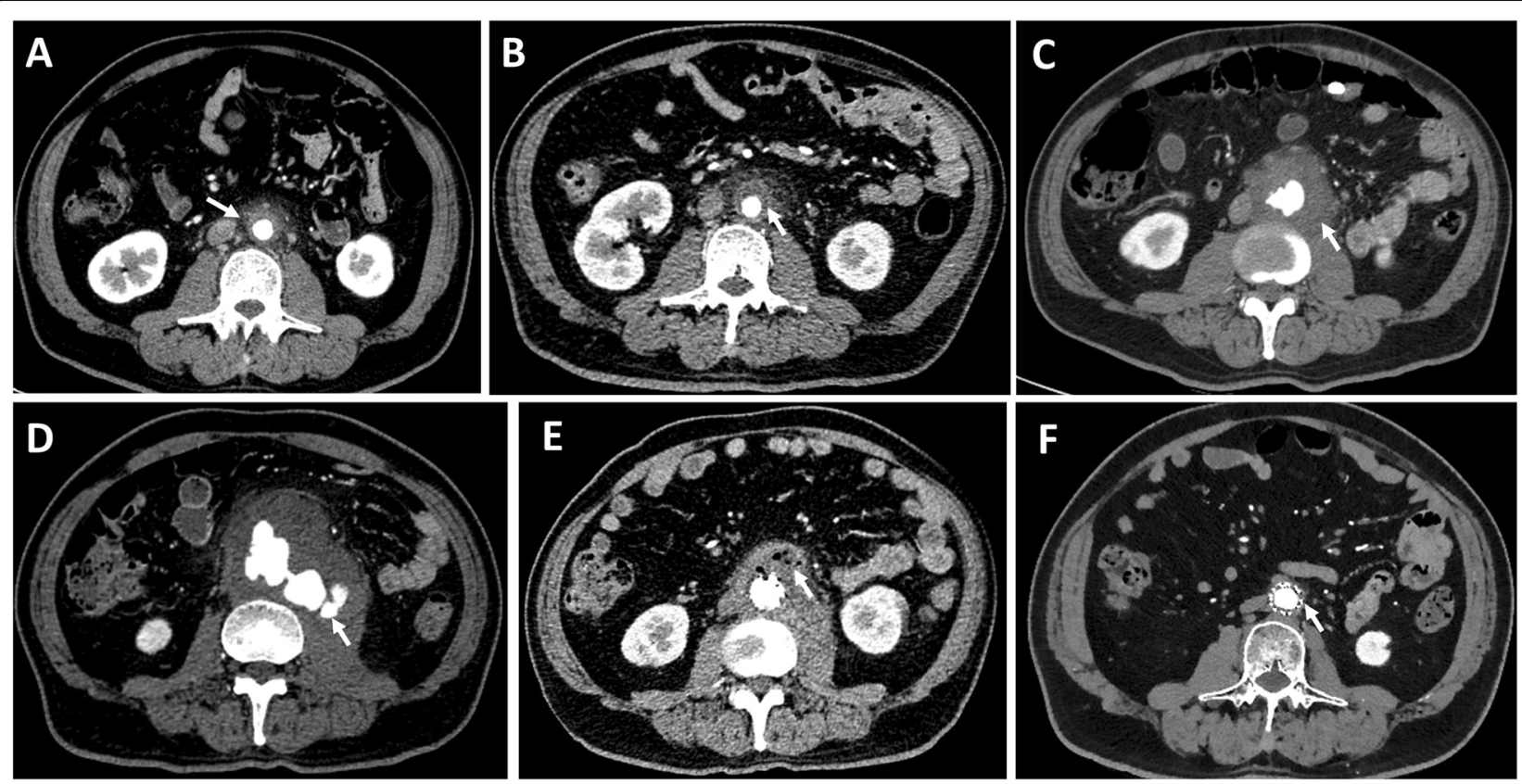

Fig. 1 CTA showed the dynamic changes (arrow) of infrarenal abdominal aorta: a a periaortic fat stranding, $\mathbf{b}$ a hypo-attenuating rim, $\mathbf{c}$ irregular soft-tissue mass, $\mathbf{d}$ a lobulated pseudoaneurysm, e postoperative left psoas muscle abscess and periaortic abscess with gas collection, and $\mathbf{f}$ normal image. CTA = computed tomography angiography

suspected, and intravenous Ciprofloxacin Lactate $(0.4 \mathrm{~g} / \mathrm{d})$ was administered empirically.

The persistence of back pain and biological inflammation led to of a CTA on day 5. It revealed an enlargement of periaortic infiltration with a hypo-attenuating rim (Fig. 1b, 2b). A magnetic resonance angiography of abdominal aorta showed thickened and enhanced aortic wall, and multiple inflammatory retroperitoneal small lymph nodes consistent with the diagnosis of aortitis (Fig. 3). The abdominal ultrasound revealed uneven thickening of the aortic wall and paraaortic soft-tissue mass with vague margin. The procalcitonin value was $0.446 \mathrm{ng} / \mathrm{mL}$, while the second time standard bacterial and mycobacterial blood cultures were still negative. On day 21, lower back pain got even worse with severe fever $\left(40^{\circ} \mathrm{C}\right)$. CTA showed a saccular aneurysm of $23.6 \mathrm{~mm}$ (Fig. 1c, 2c). The ultrasound images of abdominal aorta showed that the aortic wall locally bulged outward along with a thickened discontinuous aortic wall. Biological investigations revealed a high level of leukocyte count, C-reactive protein, erythrocyte sedimentation rate and procalcitonin $(1.1 \mathrm{ng} / \mathrm{mL})$. CTA on day 40 showed a lobulated pseudoaneurysm surrounded by enlarged mass with a left psoas muscle abscess (Fig. 1d, 2d). Considering the risk of rupture, we performed an emergency endovascular aortic repair (EVAR) and successfully excluded the aneurysm.

Fourteen days after EVAR, excision and drainage were performed for left psoas muscle abscess and periaortic abscess with gas collection (Fig. 1e, 2e). The Salmonella enteritidis was found in the bacterial culture, which confirmed the diagnosis. Based on bacterial sensitivity tests, intravenous Panipenem/Betamipron was administrated for 2 weeks. The patient recovered with normal imaging (Fig. 1f, 2f) and discharged uneventfully. The patient was regularly followed up annually, and the CTA at 2 years was normal.

\section{Discussion and conclusions}

Infectious aortic aneurysm is uncommon, representing about $0.7 \%$ of all aortic aneurysms. But it is a lifethreatening condition because these aneurysms tend to progress rapidly and are prone to rupture with high mortality [3]. Diagnosis of infectious aortic aneurysm is also a challenge for nonspecific symptoms and low positive rate of blood culture [4]. CT is considered the firstchoice imaging modality as it is available. However, the technetium-99 m/indium-111-labeled leukocyte imaging has been shown to have higher sensitivity in infectious aneurysms. The adjacent soft tissue infections increase the probability of false positivity [5]. In this case, the diagnosis was delayed because the blood culture was persistently negative, but was suspected from the rapid progression on imaging and finally confirmed by identification of Salmonella enteritidis in the paraaortic abscess drainage fluid.

The conventional treatment of infectious aortic aneurysm is usually bimodal with intensive antibiotic therapy as well 

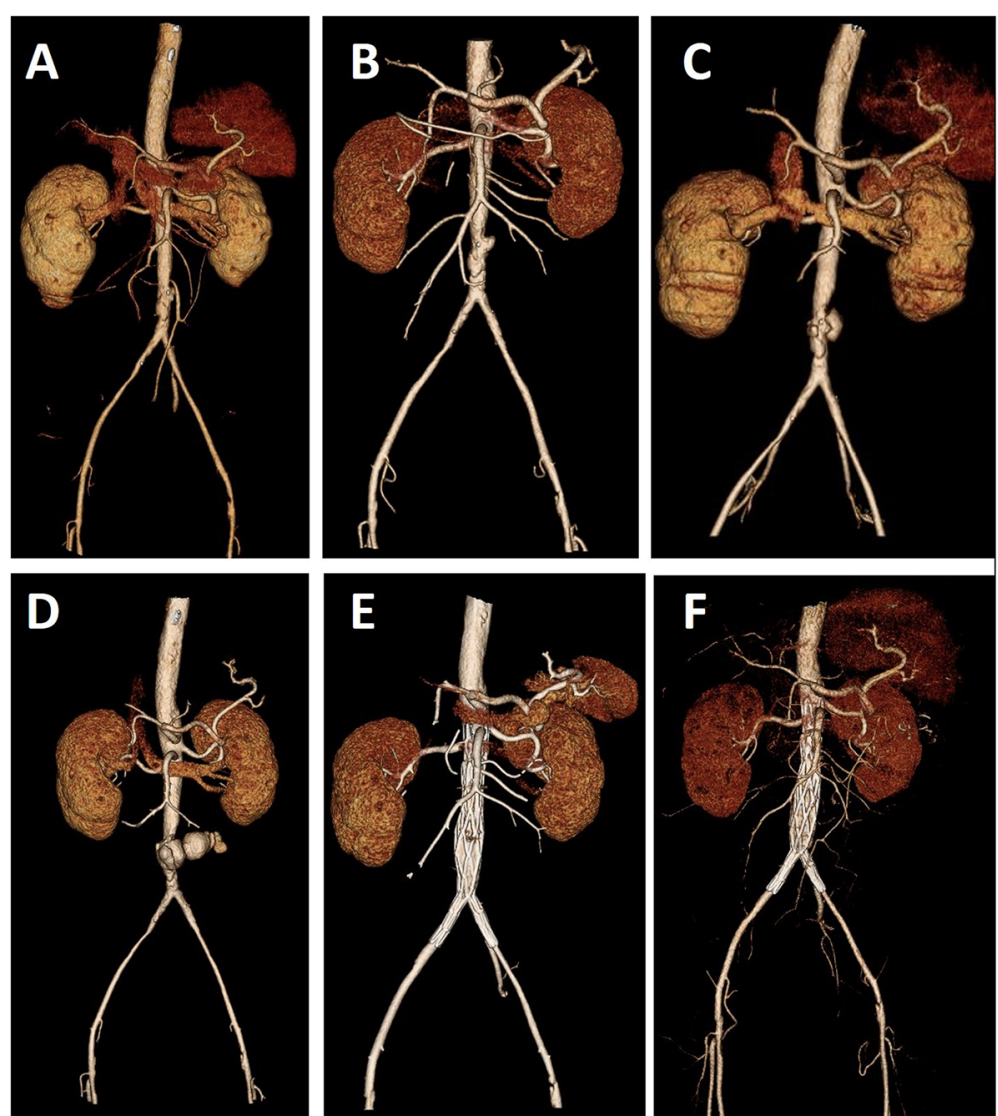

Fig. 2 CTA reconstruction of the infrarenal abdominal aorta on day 1 (a), 5 (b), 21 (c), 40 (d), 14 days after EVAR (e) and 1 year after operation (f), showing the dynamic changes of infectious aortic aneurysm. CTA = computed tomography angiography
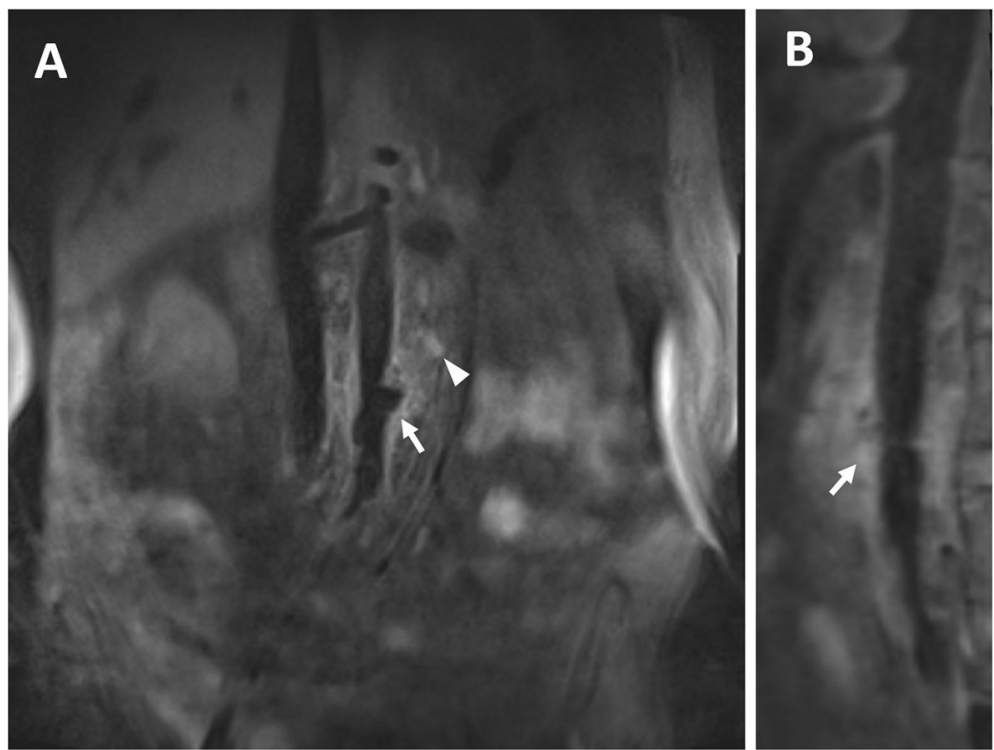

Fig. 3 MRA showed high signal intensity in the thickened aortic wall (arrow) and enlarged lymph node (arrowhead) in coronal section (a) and sagittal section (b). MRA = magnetic resonance angiography 
as surgical repair consisting of resection of the aneurysm, extensive local debridement, and revascularization by insitu reconstruction or extra-anatomic bypass. However, endovascular treatment appears to be a feasible and durable treatment alternative, and its role is growing [6]. The major concern is the risk of recurrent sepsis and infection of the endoprosthesis, as the aneurysm is not resected. Residual tissue infection may increase the risk of secondary intervention. In this case, endovascular repair was used as the first stage procedure and staged drainage was performed to remove infectious tissue. The follow-up image revealed a good aortic remolding.

Standard guidelines concerning early diagnosis, optimal intervention timing, and adequate antibiotic therapy are in need to better deal with infectious aneurysm. Awareness and recognition of imaging findings associated with infectious aneurysms are of paramount importance.

Diagnosis of infectious aortic aneurysm is difficult for nonspecific symptoms and low positive rate of blood culture. Close imaging follow up may be helpful in the diagnosis of infectious aneurysms. Endovascular repair combined with staged drainage can be feasible and effective option in selected cases.

\section{Abbreviations}

$C T$ : Computed tomography; $C T A$ : Computed tomography angiography;

EVAR: Endovascular aortic repair; MRA: Magnetic resonance angiography

\section{Acknowledgements}

Not applicable.

\section{Authors' contributions}

$\mathrm{RF}$ and JXF were major contributor in the conception and design of the work and in reviewing the manuscript. ZJL, YXZ and JJL were major contributors in reviewing and analyzing of medical records. ZXZ, ZJL and YXZ were major contributors in writing the article. ZPJ was amajor contributors in critical revision of the article. ZXZ, ZJL and YXZ participated equally and should share the equal authorship. All authors have read and approved the final manuscript.

\section{Funding}

This work was supported by the National Natural Science Foundations of China [grant numbers and funders: 81770476, Rui Feng; 81970208, Jiaxuan Feng]. The sponsors had role in the conception and design of the work, and in the decision to submit the article for publication.

\section{Availability of data and materials}

The datasets used and/or analyzed during the current study are available from the corresponding author on reasonable request.

Ethics approval and consent to participate

Ethics approval was not sought as this report contains a single case report for which patient consent was obtained.

\section{Consent for publication}

Written informed consent was obtained from the patient for publication of this case report. A copy of the written consent is available for review by the Editor-in-Chief of this journal.

\section{Competing interests}

The authors declare that they have no competing interests.

\section{Author details}

'Department of Vascular Surgery, Changhai Hospital, Navy Medical University, Changhai Road 168\#, Yangpu District, Shanghai, China. ${ }^{2}$ Department of Vascular Surgery, the First Affiliated Hospital of the Medical School of Zhejiang University, Hangzhou, China. ${ }^{3}$ Department of Vascular Surgery, the Affiliated Hospital of Qingdao University, Qingdao, Shandong, China.

Received: 28 April 2020 Accepted: 30 August 2020

Published online: 07 September 2020

\section{References}

1. Gornik HL, Creager MA. Aortitis. Circulation. 2008;117:3039-51.

2. Macedo TA, Stanson AW, Oderich GS, Johnson CM, Panneton JM, Tie ML. Infected aortic aneurysms: imaging findings. Radiology. 2004;231:250-7.

3. Oderich GS, Panneton JM, Bower TC, Cherry KJ, Rowland CM, Noel AA, et al. Infected aortic aneurysms: aggressive presentation, complicated early outcome, but durable results. J Vasc Surg. 2001;34:900-8.

4. Uchida N, Katayama A, Tamura K, Miwa S, Masatsugu K, Sueda T. In situ replacement for mycotic aneurysms on the thoracic and abdominal aorta using rifampicin-bonded grafting and omental pedicle grafting. Ann Thorac Surg. 2012;93:438-42.

5. Lyons OT, Baquneid M, Barwick TD, Bell RE, Foster N, Homer-Vanniasinkam $\mathrm{S}$, et al. Diagnosis of aortic graft infection: a case definition by the Management of Aortic Graft Infection Collaboration (MAGIC). Eur J Vasc Endovasc Surg. 2016;52:758-63.

6. Sörelius K, Mani K, Björck M, Sedivy P, Wahlgren CM, Taylor P, et al. Endovascular treatment of mycotic aortic aneurysms: a European multicenter study. Circulation. 2014;130:2136-42.

\section{Publisher's Note}

Springer Nature remains neutral with regard to jurisdictional claims in published maps and institutional affiliations.
Ready to submit your research? Choose BMC and benefit from:
- fast, convenient online submission
- thorough peer review by experienced researchers in your field
- rapid publication on acceptance
- support for research data, including large and complex data types
- gold Open Access which fosters wider collaboration and increased citations
- maximum visibility for your research: over $100 \mathrm{M}$ website views per year
At BMC, research is always in progress.
Learn more biomedcentral.com/submission 